Wright State University

CORE Scholar

8-1-2004

\title{
C02+ Dissociative Recombination: A Source of Thermal and Nonthermal C on Mars
}

Jane L. Fox

Wright State University - Main Campus, jane.fox@wright.edu

Follow this and additional works at: https://corescholar.libraries.wright.edu/physics

Part of the Physics Commons

\section{Repository Citation}

Fox, J. L. (2004). CO2+ Dissociative Recombination: A Source of Thermal and Nonthermal C on Mars. Journal of Geophysical Research-Space Physics, 109, A08306.

https://corescholar.libraries.wright.edu/physics/21

This Article is brought to you for free and open access by the Physics at CORE Scholar. It has been accepted for inclusion in Physics Faculty Publications by an authorized administrator of CORE Scholar. For more information, please contact library-corescholar@wright.edu. 


\title{
$\mathrm{CO}_{2}^{+}$dissociative recombination: A source of thermal and nonthermal $\mathrm{C}$ on Mars
}

\author{
J. L. Fox \\ Department of Physics, Wright State University, Dayton, Ohio, USA \\ Received 30 March 2004; accepted 2 June 2004; published 14 August 2004.
}

[1] $\mathrm{CO}_{2}^{+}$dissociative recombination has been assumed in the past to proceed overwhelmingly by the channel that produces $\mathrm{CO}+\mathrm{O}$. Although the channel that leads to the products $\mathrm{C}+\mathrm{O}_{2}$ is energetically possible, the significant rearrangement of bonds that is required has led to the belief that this channel contributes minimally. Seiersen et al. [2003] have recently measured the branching ratio for the latter channel, and they have reported a value of $\sim 9 \%$ of the total. We have constructed both low and high solar activity models of the Martian thermosphere, and we have tested the effect of including the $\mathrm{C}+\mathrm{O}_{2}$ channel on the production of both thermal and escaping $\mathrm{C}$ atoms in the Martian atmosphere. We find that dissociative recombination of $\mathrm{CO}_{2}^{+}$is by far the dominant source of atomic carbon in both models, and its inclusion leads to larger densities of ambient $\mathrm{C}$. The contribution of the source to the escape flux of C, however, is found to be small, both because the altitude profile of the production rate falls off rapidly near the exobase and because the $\mathrm{O}_{2}$ molecule is probably produced with considerable internal energy. A calculation of the statistical energy partitioning into vibrational and rotational energy of the product $\mathrm{O}_{2}$ molecule and the translational energy of the products of the reaction indicates that the $\mathrm{C}$ atom is produced with translational energy exceeding the escape energy only $3.7 \%$ of the time. The models predict that photodissociation of $\mathrm{CO}$ is the most important source of escaping $\mathrm{C}$, as have other recent investigations. The computed escape fluxes for the minor sources, however, differ considerably from those of previous models. We find that the second most important source of escaping $\mathrm{C}$ is electron impact dissociation of $\mathrm{CO}$, followed by dissociative recombination of $\mathrm{CO}^{+}$. The total predicted escape fluxes are comparable to those of previous models at high solar activity and are a factor of 2 larger at low solar activity. INDEX TERMS: 5405 Planetology: Solid Surface Planets: Atmospheres - composition and chemistry; 5407 Planetology: Solid Surface Planets: Atmospheresevolution; 5435 Planetology: Solid Surface Planets: Ionospheres (2459); 2459 Ionosphere: Planetary ionospheres $(5435,5729,6026,6027,6028)$; KEYWORDS: Martian ionosphere, dissociative recombination, atomic carbon, atmospheric escape, Martian thermosphere

Citation: Fox, J. L. (2004), $\mathrm{CO}_{2}^{+}$dissociative recombination: A source of thermal and nonthermal C on Mars, J. Geophys. Res., 109, A08306, doi:10.1029/2004JA010514.

\section{Introduction}

[2] The ultraviolet spectrometers on the Mariner 6 and 7 flyby spacecraft and the Mariner 9 orbiter detected the resonance multiplets of atomic carbon at $1561 \AA\left({ }^{3} D_{J}^{o} \rightarrow\right.$ $\left.{ }^{3} P_{J}\right)$ and $1657 \AA\left({ }^{3} P_{J}^{o} \rightarrow{ }^{3} P_{J}\right)$ in the Martian dayglow spectra [Barth et al., 1971, 1972a, 1972b]. For the highsolar activity period of Mariner 6 and 7 flybys, Barth et al. [1971] reported an average maximum limb intensity for the $1657 \AA$ feature of $\sim 1.7 \mathrm{kR}$, which corresponds to an overhead intensity of $\sim 350 \mathrm{R}$. The potential mechanisms for production of atomic carbon in the ground and excited states are photodissociation and electron impact dissociation of $\mathrm{CO}_{2}$ and $\mathrm{CO}$, photodissociative ionization and electron impact dissociative ionization of $\mathrm{CO}_{2}$ and $\mathrm{CO}$, and disso-

Copyright 2004 by the American Geophysical Union. 0148-0227/04/2004JA010514 ciative recombination of $\mathrm{CO}^{+}$and $\mathrm{CO}_{2}^{+}$. Excited states of atomic carbon may be produced by electron impact excitation of ambient $\mathrm{C}$ and, for states connected to the ground state by allowed transitions, by resonance scattering of solar radiation. Although their pre-Viking models were flawed by lack of data both about the Martian thermosphere and about atomic and molecular processes, McElroy and McConnell [1971] identified the main sources of atomic carbon in the thermospheres of Mars and Venus. They predicted a maximum $C$ density on Mars in the range $(3-5) \times 10^{4} \mathrm{~cm}^{-3}$, and they computed an intensity at $1657 \AA$ due to resonance scattering of $10 \mathrm{R}$. They concluded that electron impact dissociation and photodissociation of $\mathrm{CO}_{2}$ were the most important sources of both the ground and excited states of atomic carbon.

[3] Fox and Dalgarno [1979] constructed a model of the Martian dayglow on the basis of neutral density profiles from the Viking 1 lander [Nier and McElroy, 1976; McElroy 
et al., 1976]. They predicted integrated overhead emission rates due to photodissociative excitation and electron impact dissociative excitation of $\mathrm{CO}_{2}$ of 15 and $8 \mathrm{R}$ for the 1657 and $1561 \AA$ multiplets, respectively, and showed that these mechanisms could not account for the observed intensities. Using the Viking-measured abundance of CO, $\sim 0.42 \%$, Krasnopolsky [1982] found that photodissociation of CO was the most important source of $\mathrm{C}$ in the Martian thermosphere and was even more important on Venus, where the thermospheric CO mixing ratios are larger [cf. Fox, 1982]. The destruction of $\mathrm{C}$ is dominated by reaction with $\mathrm{O}_{2}$, and thus the $\mathrm{O}_{2}$ densities are important in determining the $\mathrm{C}$ densities. The Viking neutral mass spectrometers measured an $\mathrm{O}_{2}$ abundance of $\sim 0.012$ at the Martian homopause. Krasnopolsky [1982] predicted an atomic carbon density profile that peaked near $150 \mathrm{~km}$, with a value of $\sim 2 \times$ $10^{5} \mathrm{~cm}^{-3}$ at high solar activity, and he showed that his calculated limb profile for the $1657 \AA$ emission approached those that were measured by the Mariner ultraviolet spectrometers. Later models of the Martian thermosphere by Fox et al. [1995] predicted peak densities of C on Mars that varied from $\sim 6.2 \times 10^{4}$ to $\sim 2 \times 10^{5} \mathrm{~cm}^{-3}$ near $150 \mathrm{~km}$ from low to high solar activity.

[4] One of the sources of atomic carbon suggested by McElroy and McConnell [1971] was the dissociative recombination of $\mathrm{CO}_{2}^{+}$. Usually, this process has been assumed to proceed via the channel

$$
\mathrm{CO}_{2}^{+}+e \rightarrow \mathrm{CO}+\mathrm{O}+8.3 \mathrm{eV}
$$

although the product $\mathrm{CO}$ and $\mathrm{O}$ fragments have been found to be formed in excited states a substantial fraction of the time [e.g., Wauchop and Broida, 1972; Gutcheck and Zipf, 1973; Tsuji et al., 1995; Skrzypkowski et al., 1998]. Because of the significant rearrangement of bonds that must take place, the branching ratio for the channel

$$
\mathrm{CO}_{2}^{+}+e \rightarrow \mathrm{C}+\mathrm{O}_{2}+2.3 \mathrm{eV}
$$

has been assumed to be negligible. McElroy and McConnell [1971] included this source with an estimated rate coefficient of $1 \times 10^{-10} \mathrm{~cm}^{3} \mathrm{~s}^{-1}$, which corresponds to a branching ratio of $<0.001$ for electron temperatures up to $\sim 3000 \mathrm{~K}$. The channel that forms a $\mathrm{CO}_{2}$ molecule,

$$
\mathrm{CO}_{2}^{+}+e \rightarrow \mathrm{CO}_{2}+13.76 \mathrm{eV}
$$

is not allowed at low pressures by conservation of energy and momentum unless a photon is emitted in the process. At high pressures, reaction (1c) could proceed by three-body recombination. The channel that leads to total breakup of the $\mathrm{CO}_{2}^{+}$ion,

$$
\mathrm{CO}_{2}^{+}+e \rightarrow \mathrm{C}+\mathrm{O}+\mathrm{O}-2.8 \mathrm{eV}
$$

is energetically forbidden.

[5] Seiersen et al. [2003] have recently carried out measurements of the rate coefficient and products of dissociative recombination of $\mathrm{CO}_{2}^{+}$with the Aarhus storage ring in Denmark. The use of ion storage rings in determining the branching ratios from dissociative recombination of molecular ions has been discussed by Larsson [1997]. Seiersen et al. [2003] have reported a rate coefficient for reaction $(1)$ of $6.4 \times 10^{-7}\left(300 / T_{e}\right)^{0.8} \mathrm{~cm}^{3} \mathrm{~s}^{-1}$. This value is larger at thermal energies than the values measured in the flowing afterglow Langmuir probe experiments of $3.1 \times$ $10^{-7} \mathrm{~cm}^{3} \mathrm{~s}^{-1}$ reported by Geoghegan et al. [1991] and $3.5 \times 10^{-7} \mathrm{~cm}^{3} \mathrm{~s}^{-1}$ reported by Gougousi et al. [1997]. We adopted the latter rate coefficient with the theoretical temperature dependence of $\left(300 / T_{e}\right)^{0.5}$ in our recent models of the Martian and Venusian ionospheres [e.g., Fox and Sung, 2001; Fox and Bakalian, 2001; Fox, 2003a; J. L. Fox, Response of the Martian thermosphere/ionosphere to enhanced fluxes of solar soft X-rays, submitted to Journal of Geophysical Research, 2004, hereinafter referred to as Fox, submitted manuscript, 2004]. If this temperature dependence is assumed, the rate coefficients of Gougousi et al. [1997] and Seiersen et al. [2003] are comparable for electron temperatures in the range $1500-3000 \mathrm{~K}$, which prevail in the Martian upper ionosphere. Seiersen et al. [2003] reported branching ratios of $0.87 \pm 0.04,0.09 \pm 0.03$, and $0.04 \pm 0.03$ for reactions (1a) $-(1 \mathrm{c})$. This is the first reported detection of reaction $(1 \mathrm{~b})$ in measurements of dissociative recombination of $\mathrm{CO}_{2}^{+}$.

[6] Here we investigate the effect of the measured yield of the channel in reaction ( $1 \mathrm{~b})$ on the $\mathrm{C}$ density profiles in models of the Martian thermosphere. Here we have adopted the rate coefficient for $\mathrm{CO}_{2}^{+}$dissociative recombination (reaction (1)) measured by Seiersen et al. [2003]. Since reaction (1c) is not expected, we have adopted slightly different branching ratios for reactions (1a), (1b), and (1c) of $0.907,0.093$, and 0.0 , respectively.

\section{Models}

\subsection{Neutral Densities}

[7] We have constructed low and high solar activity models that are similar to those of our recent investigations [e.g., Fox, 2003a, also submitted manuscript, 2004]. The background neutral models contain 12 species, including $\mathrm{CO}_{2}, \mathrm{Ar}, \mathrm{N}_{2}, \mathrm{O}, \mathrm{CO}, \mathrm{O}_{2}, \mathrm{He}, \mathrm{H}, \mathrm{H}_{2}, \mathrm{C}, \mathrm{N}$, and $\mathrm{NO}$. The low solar activity model is based on that of Viking, and the high solar activity model is based on the Mars Thermospheric General Circulation Model (MTGCM) of Bougher et al. [1990, 1999, 2000, also personal communication, 1999]. An $\mathrm{H}_{2}$ abundance of $15 \pm 5$ ppm was reported by Krasnopolsky and Feldman [2001] from the intensities of the $(6,3)$ and $(6,1) \mathrm{H}_{2}$ Lyman $\left(B^{1} \Sigma_{u}^{+} \rightarrow X^{1} \Sigma_{g}^{+}\right)$bands measured using the Far Ultraviolet Spectrometry Explorer. Here we have adjusted the upward flux of $\mathrm{H}_{2}$ at the lower boundary of $80 \mathrm{~km}$ so that the resulting mixing ratio of $\mathrm{H}_{2}$ is $\sim 10 \mathrm{ppm}$. This abundance is within the stated uncertainty of the measurements, and the use of the smaller value results in significantly better agreement between the model $\mathrm{O}^{+}$density profiles and those derived from the Viking retarding potential analyzer (RPA) data [Hanson et al., 1977]. The $\mathrm{H}_{2}$ upward fluxes at $80 \mathrm{~km}$ are $(6.1-9.0) \times 10^{7} \mathrm{~cm}^{-2} \mathrm{~s}^{-1}$, where the range is from low to high solar activity. The $\mathrm{H}$ density profile was computed by fixing the density at $80 \mathrm{~km}$ to a value that approximated the densities near $250 \mathrm{~km}$ inferred from the Mariner 6 and 7 Lyman alpha dayglow measurements at high solar activity [e.g., Anderson and Hord, 1971] and the low solar activity values inferred from 
the Hubble Space Telescope measurements of Krasnopolsky et al. [1998]. Our computed $\mathrm{H}$ densities at $250 \mathrm{~km}$ are $3 \times$ $10^{5} \mathrm{~cm}^{-3}$ at low solar activity and $3 \times 10^{4} \mathrm{~cm}^{-3}$ at high solar activity.

[8] The densities of $\mathrm{C}, \mathrm{N}$, and $\mathrm{NO}$ were computed selfconsistently in the models. The lower boundary conditions were downward fluxes for $\mathrm{N}$ and $\mathrm{NO}$ and zero flux for $\mathrm{C}$. Although NO is known to be a source of odd nitrogen to the middle atmosphere, the values of the fluxes are uncertain. We have adopted fluxes of approximately $-2 \times 10^{7} \mathrm{~cm}^{-2} \mathrm{~s}^{-1}$ at low solar activity and approximately $-8 \times 10^{7} \mathrm{~cm}^{-2} \mathrm{~s}^{-1}$ at high solar activity. These values were chosen according to the requirements that the computed densities be positive and the downward velocities be less than $K / H$, where $K$ is the eddy diffusion coefficient and $H$ is the atmospheric scale height. No fine tuning was done. The computed density profiles of $\mathrm{NO}$ and $\mathrm{N}$ below $\sim 90 \mathrm{~km}$ are thus somewhat uncertain. Zero flux boundary conditions were adopted at the tops of the models at $400 \mathrm{~km}$ for all the neutral species except $\mathrm{H}$ and $\mathrm{H}_{2}$, for which Jeans escape velocities were assumed. The Jeans velocities are given by

$$
v_{\mathrm{J}}=B \frac{u}{2 \sqrt{\pi}}(1+\lambda) \exp (-\lambda)
$$

where $u=(2 k T / m)^{1 / 2}$ is the modal velocity; $\lambda$ is the gravitational potential energy in units of $k T$, where $k$ is Boltzmann's constant and $T$ is temperature;

$$
\lambda=\frac{m g r}{k T}=\frac{r}{H},
$$

where $m$ is the mass of the particle, $r$ is the radius of the planet, and $g$ is the acceleration of gravity; and $B$ is a correction factor that accounts for the suppression of the tail of the distribution due to escape of energetic particles [e.g., Chamberlain, 1963]. The $B$ factor has been shown to depend on the planet and on the temperature. A value of $\sim 0.5$ was adopted for Mars, as suggested by the calculations of Shizgal and Blackmore [1986]. The rate coefficients adopted here, other than that for the $\mathrm{CO}_{2}^{+}$dissociative recombination reaction, are largely the same as those of Fox and Sung [2001] and Fox [2003a, also submitted manuscript, 2004].

\subsection{Solar Fluxes}

[9] We adopted the 76200 and 79050 solar fluxes for low and high solar activities, respectively, from the Solar 2000 (S2K) v1.24a model of Tobiska [2004, also personal communications, 2003, 2004]. The EUV fluxes were normalized to the soft X-ray fluxes measured by the Student Nitric Oxide Explorer (SNOE) solar X-ray photometer (SXP) [e.g., Barth et al., 1999; Bailey et al., 2000]. The S2K v2.2x models, which are normalized to the measurements of the Thermosphere Ionosphere Mesosphere Energetics and Dynamics mission Solar EUV Experiment instrument [e.g., Woods et al., 2000], are still evolving and will be used in future models when the normalization is more certain. In the versions of the solar spectra that we adopted the photon fluxes are given as delta functions at the strong solar lines and at $1 \AA$ intervals in the continuum from 18 to $2000 \AA$ for a total of 1811 wavelengths. Below $18 \AA$ we have adopted the solar fluxes from Ayres [1997, also private communi- cation, 1996]. These harder X-ray solar fluxes are highly variable but are absorbed at altitudes less than $\sim 100 \mathrm{~km}$, which is outside the region of interest in this model. A solar zenith angle of $60^{\circ}$ and an average heliocentric distance of $1.523 \mathrm{AU}$ were adopted.

\subsection{Ion Densities}

[10] The cross sections we have employed for photoabsorption, photoionization, photodissociation, and photoelectron impact processes are the same as those which have been presented previously [e.g., Fox, 1993; Fox et al., 1995; Fox and Sung, 2001; Fox, submitted manuscript, 2004]. The photoelectron grid extends from 0 to $600 \mathrm{eV}$ in $1 \mathrm{eV}$ intervals. Auger processes are included for $\mathrm{O}, \mathrm{C}$, and $\mathrm{N}$ atoms. The $K$ shell cross sections for all the atoms are taken from Verner and Yakovlev [1995], and those for molecules are considered to be the sum of the individual atoms of which they are composed.

[11] All the ions were assumed to be in photochemical equilibrium at the lower boundary. At the upper boundaries, upward velocities of $8 \times 10^{4} \mathrm{~cm} \mathrm{~s}^{-1}$ at low solar activity and $1.2 \times 10^{5} \mathrm{~cm} \mathrm{~s}^{-1}$ at high solar activity were imposed on all the ions except $\mathrm{O}^{++}$, which was assumed to be in photochemical equilibrium. The upward velocity at low solar activity is in substantial agreement with those found necessary in previous models to reproduce the Viking $\mathrm{O}_{2}^{+}$profile [Chen et al., 1978; Fox, 1993, 1997]. These upward fluxes in a one-dimensional model probably represent the divergence of the horizontal ion fluxes [e.g., Shinagawa and Cravens, 1989]. Substantial transterminator fluxes of ions have been predicted in the MHD models of the interaction of the solar wind with the Martian thermosphere of Ma et al. [2002] [see also Liu et al., 2001].

[12] The computed ion density profiles are shown in Figures 1 and 2. In Figure 1 the model densities are compared to those inferred from the Viking 1 RPA [Hanson et al., 1977]. Because Viking 1 entered the atmosphere at a slightly smaller solar zenith angle of $44^{\circ}$ and a larger heliocentric distance of $1.648 \mathrm{AU}$, only a rough comparison is valid. The agreement between the measured and model $\mathrm{O}_{2}^{+}$and $\mathrm{CO}_{2}^{+}$profiles is fairly good. The computed $\mathrm{O}^{+}$density profile peaks at $\sim 600 \mathrm{~cm}^{-3}$ near $220 \mathrm{~km}$ in substantial agreement with the Viking measured peak densities of $600-700 \mathrm{~cm}^{-3}$ in the $220-230 \mathrm{~km}$ region. At higher altitudes the model densities of $\mathrm{O}^{+}$are underestimated by $\sim 35 \%$. Below the main peak in the computed $\mathrm{O}_{2}^{+}$density profiles a lower peak is predicted that attains densities of $6.7 \times 10^{4} \mathrm{~cm}^{-3}$ near $111 \mathrm{~km}$ at low solar activity and $1.34 \times 10^{5} \mathrm{~cm}^{-3}$ near $117 \mathrm{~km}$ at high solar activity. Such peaks, which are due to the absorption of soft X-rays, have been seen in many of the radio occultation profiles measured by the Mars Global Surveyor (MGS) radio science experiment (D. Hinson and the MGS Radio Science Team, available at http://nova. stanford.edu/projects/mgs/eds-public.html) but were not seen in the Viking RPA measurements. A lower shoulder in electron density profile of $\sim 8 \times 10^{4} \mathrm{~cm}^{-3}$ was measured by the radio occultation experiment on Mariner 6 [Fjeldbo et al., 1970]. The MGS profiles show a variability of about a factor of 2 in the lower peak during a single occultation season. A direct comparison is not possible because the 


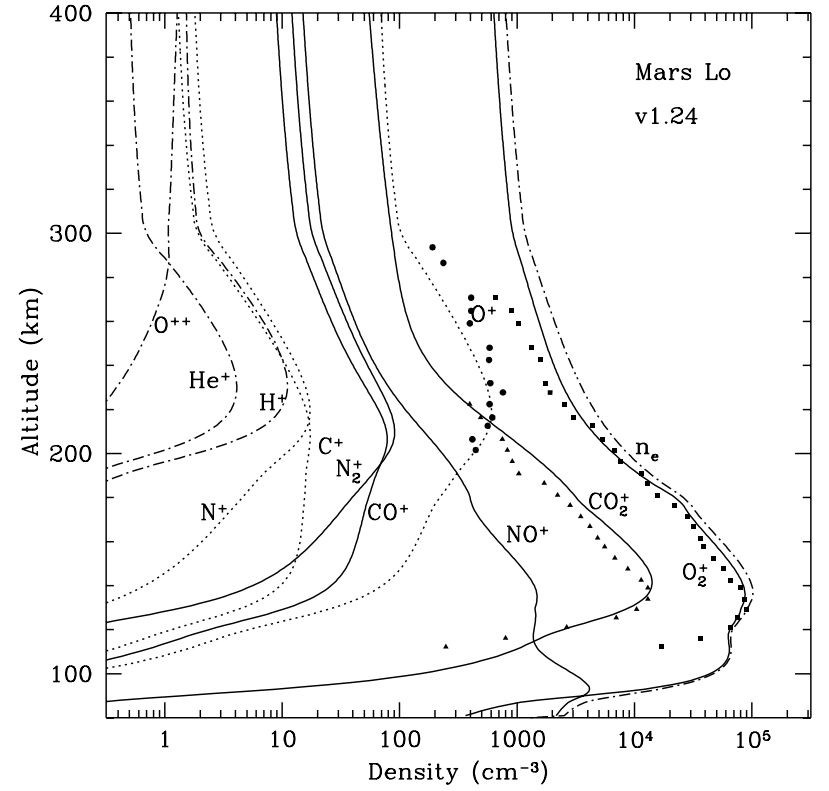

Figure 1. Ion density profiles for the low solar activity model. The solid curves are molecular ion density profiles, and the dotted and dot-dashed curves are atomic ion density profiles. The electron density profile is also shown as a dotdashed curve. Squares, triangles, and circles are the densities of $\mathrm{O}_{2}^{+}, \mathrm{CO}_{2}^{+}$, and $\mathrm{O}^{+}$, respectively, measured by the Viking retarding potential analyzer [Hanson et al., 1977].

MGS electron density profiles pertain to large solar zenith angles.

\section{Atomic Carbon Densities}

\subsection{Production and Loss Processes}

[13] The production rates of atomic carbon are shown in Figures 3 and 4 for the low and high solar activity models, respectively. Figures 3 and 4 (top) show the sources due to photon absorption and photoelectron impact. At both low and high solar activities, photodissociation of $\mathrm{CO}$ dominates the production above $\sim 130 \mathrm{~km}$; the peak production rates are $\sim 12$ and $\sim 48 \mathrm{~cm}^{-3} \mathrm{~s}^{-1}$ at 140 and $150 \mathrm{~km}$, respectively. Below $130 \mathrm{~km}$, electron impact dissociation of $\mathrm{CO}$ and $\mathrm{CO}_{2}$ dominates. We should note here that the production rates from electron impact dissociation of $\mathrm{CO}_{2}$ include only excited carbon, and the total production rate of atomic $\mathrm{C}$ may be larger.

[14] Atomic carbon is produced in several chemical reactions, including dissociative recombination of $\mathrm{CO}^{+}$,

$$
\mathrm{CO}^{+}+e \rightarrow \mathrm{C}+\mathrm{O},
$$

and dissociative charge transfer from $\mathrm{O}^{++}$,

$$
\mathrm{O}^{++}+\mathrm{CO}_{2} \rightarrow \mathrm{C}+\mathrm{O}+2 \mathrm{O}^{+} \text {. }
$$

The products of the reaction of $\mathrm{O}^{++}$with $\mathrm{CO}_{2}$ are unknown, but the large amount of energy available makes the production of energetic fragments highly probable. We have assumed that the branching ratio for the production of C in reaction (3) is 0.25 [cf. Fox and Victor, 1981]. Other potentially important sources of atomic carbon include the ion-molecule reactions

$$
\begin{aligned}
& \mathrm{N}^{+}+\mathrm{CO} \rightarrow \mathrm{NO}^{+}+\mathrm{C}, \\
& \mathrm{CO}^{+}+\mathrm{N} \rightarrow \mathrm{NO}^{+}+\mathrm{C}, \\
& \mathrm{C}^{+}+\mathrm{NO} \rightarrow \mathrm{NO}^{+}+\mathrm{C} .
\end{aligned}
$$

The production rate profiles for the chemical sources of atomic carbon are shown in Figures 3 and 4 (bottom) for low and high solar activities, respectively. Dissociative recombination of $\mathrm{CO}_{2}^{+}$clearly dominates the chemical production between the altitudes of $\sim 90$ and $220-240 \mathrm{~km}$, with peak production rates of $115-313 \mathrm{~cm}^{-3} \mathrm{~s}^{-1}$ at $137-$ $138 \mathrm{~km}$, where the ranges are from low to high solar activities. As Figures 3 and 4 show, dissociative recombination of $\mathrm{CO}_{2}^{+}$is the most important source of $\mathrm{C}$ atoms near the peak of the production rate profile. The total integrated column production rates of $\mathrm{C}$ due to various sources are presented in Table 1.

[15] Loss of $\mathrm{C}$ is dominated by the reaction with $\mathrm{O}_{2}$ :

$$
\mathrm{C}+\mathrm{O}_{2} \rightarrow \mathrm{CO}+\mathrm{O} .
$$

The contributions of reactions with NO

$$
\begin{aligned}
& \mathrm{C}+\mathrm{NO} \rightarrow \mathrm{CN}+\mathrm{O} \\
& \mathrm{C}+\mathrm{NO} \rightarrow \mathrm{CO}+\mathrm{N}
\end{aligned}
$$

are limited to $\sim 10 \%$ of the loss rate arising from reaction (7).

\subsection{Density Profiles}

[16] The computed density profiles of minor neutrals, including atomic carbon in the models, are shown in

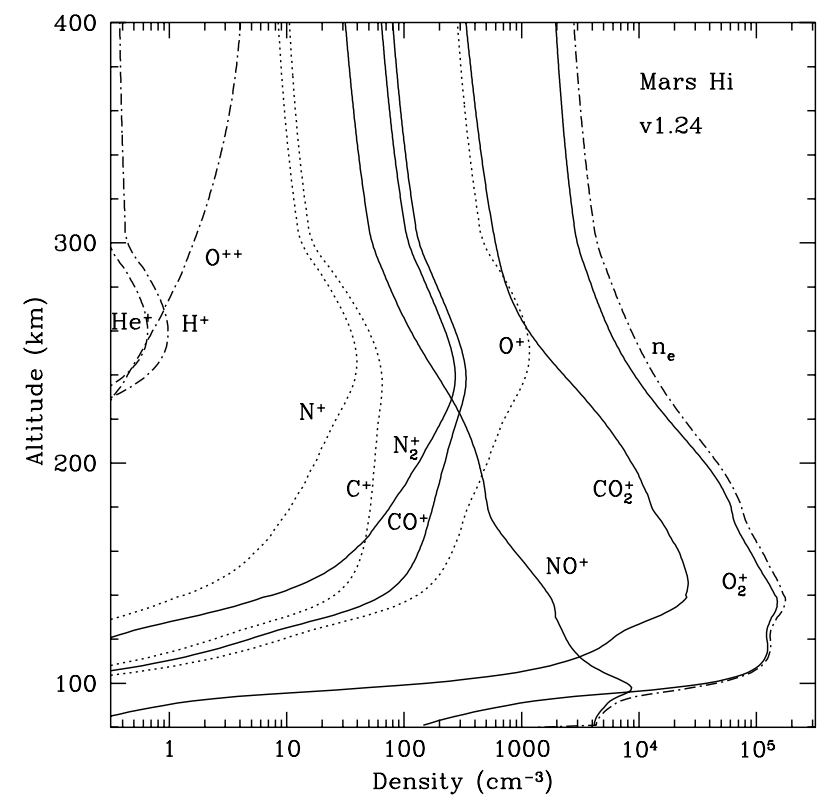

Figure 2. Same as for Figure 1 but for the high solar activity model. 

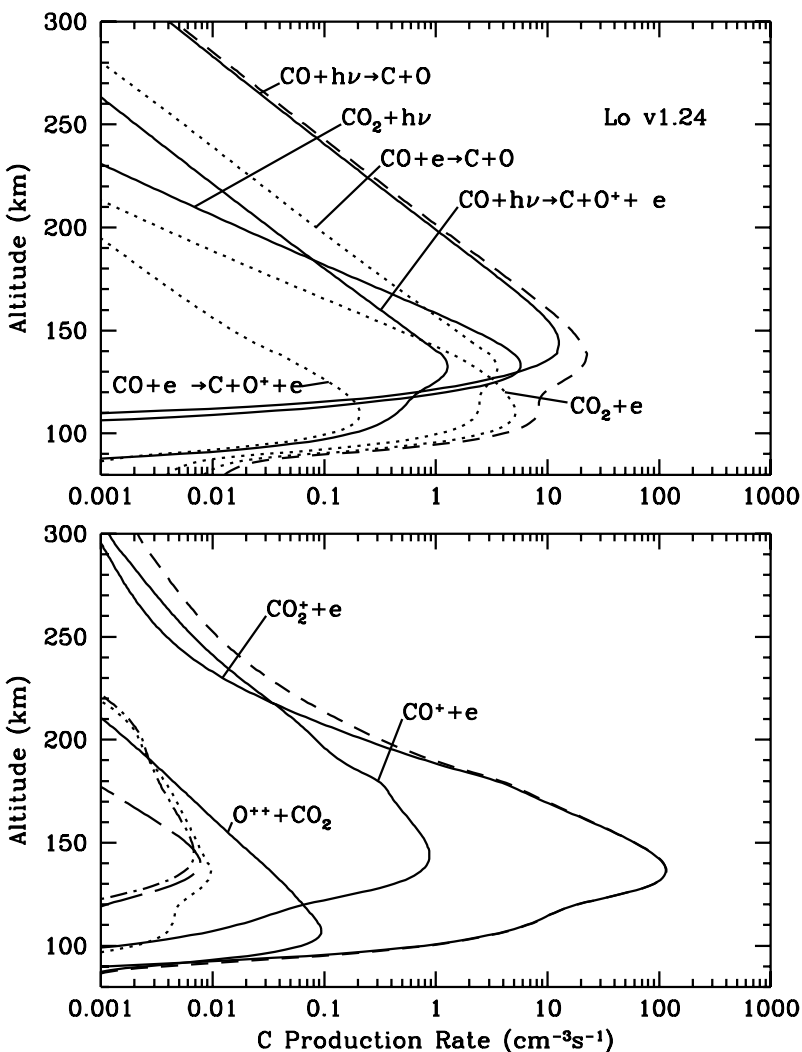

Figure 3. Production rate profiles for atomic carbon for the low solar activity model. "Lo v1.24" refers to the solar fluxes adopted: the 76200 Solar 2000 v1.24 spectrum of Tobiska [2004] (see text). (top) Production rates by photons (solid curves) and by photoelectrons (dotted curves). The total production rate is given by the dashed curve. (bottom) Production rate profiles of $\mathrm{C}$ in chemical reactions. The solid curves are labeled. The dotted curve is the source due to the reaction of $\mathrm{N}^{+}+\mathrm{CO}$ (reaction (4)), the dot-dashed curve is the production profile due to the reaction of $\mathrm{CO}^{+}+\mathrm{N}$ (reaction (5)), and the long-dashed curve is the production profile due to the reaction of $\mathrm{C}^{+}+\mathrm{NO}$ (reaction (6)). The short-dashed curve represents the total production rate.

Figures 5 and 6 . The predicted peak carbon densities for the low and high solar activity models are $9.5 \times 10^{4} \mathrm{~cm}^{-3}$ at $\sim 145 \mathrm{~km}$ and $2.1 \times 10^{5} \mathrm{~cm}^{-3}$ at $153 \mathrm{~km}$, respectively. The atomic carbon density peaks for similar models without the $\mathrm{CO}_{2}^{+}$dissociative recombination source are $2.5 \times 10^{4}$ and $1.2 \times 10^{5} \mathrm{~cm}^{-3}$ at low and high solar activities, respectively [Fox, 2003b]. If the branching ratio for production of atomic carbon in dissociative recombination of $\mathrm{CO}_{2}^{+}$is of the order of 0.09 , the atomic carbon densities in the thermosphere of Mars will be significantly larger than if the reaction is assumed not to occur. The peak density of $\mathrm{C}$ would be larger in the high solar activity model if smaller eddy diffusion coefficients $K$ were chosen. In the present model we adopted a value for $K$ of $1.4 \times 10^{14} / n^{1 / 2}$, where $n$ is the total number density. We chose this value as a best fit for the $\mathrm{N}_{2}$ density profile in the high solar activity MTGCM. Smaller values of $K$ would yield larger peak densities of C. We would expect similar but less dramatic effects on Venus because the larger mixing ratio of $\mathrm{CO}$ in the Venusian thermosphere
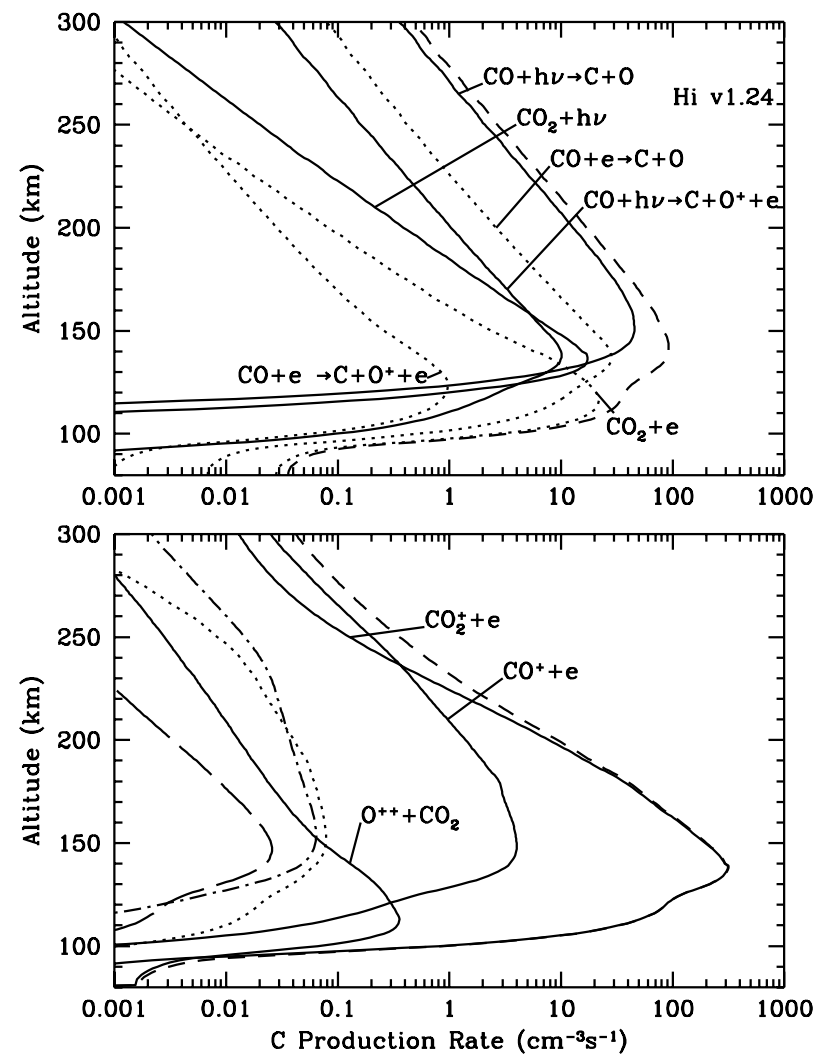

Figure 4. Production rate profiles of atomic carbon for the high solar activity model. "Hi v1.24" refers to the solar fluxes used in the model: the 79050 Solar 2000 v1.24 spectrum of Tobiska [2004] (see text). (top) Production rate profiles due to photon and photoelectron impact. (bottom) Production rate profiles due to chemical reactions. The different curves represent the various processes as in Figure 3.

increases the importance of photodissociation and electron impact dissociation of $\mathrm{CO}$ relative to chemical reactions.

\section{Nonthermal Atomic Carbon}

[17] The exothermicity of reaction (1b) for $\mathrm{O}_{2}$ in the ground vibrational and rotational states is $2.3 \mathrm{eV}$, with $73 \%$

Table 1. Column Production Rates of C Atoms Due to Various Sources for the Low and High Solar Activity Models ${ }^{\mathrm{a}}$

\begin{tabular}{lcc}
\hline \multicolumn{1}{c}{ Mechanism } & Low Solar Activity & High Solar Activity \\
\hline $\mathrm{CO}_{2}^{+}+e \rightarrow \mathrm{C}+\mathrm{O}_{2}$ & $3.2(2)^{\mathrm{b}}$ & $1.07(3)$ \\
$\mathrm{CO}+\mathrm{h} \nu \rightarrow \mathrm{C}+\mathrm{O}$ & $5.0(1)$ & $2.5(2)$ \\
$\mathrm{CO}+e \rightarrow \mathrm{C}^{*}+e+$ products & $1.66(1)$ & $6.5(1)$ \\
$\mathrm{CO}+e \rightarrow \mathrm{C}+\mathrm{O}+e$ & $1.58(1)$ & $1.28(2)$ \\
$\mathrm{CO}+\mathrm{h} \nu \rightarrow \mathrm{C}^{*}+$ products & $1.49(1)$ & $4.8(1)$ \\
$\mathrm{CO}+\mathrm{h} \nu \rightarrow \mathrm{C}+\mathrm{O}^{+}+e$ & $4.9(0)$ & $4.4(1)$ \\
$\mathrm{CO}+e \rightarrow \mathrm{C}+\mathrm{O}$ & $3.9(0)$ & $2.5(1)$ \\
$\mathrm{CO}+e \rightarrow \mathrm{C}+\mathrm{O}^{+}+2 e$ & $6.2(-1)$ & $3.6(0)$ \\
$\mathrm{O}^{++}+\mathrm{CO} \rightarrow \mathrm{C}+\mathrm{O}+2 \mathrm{O}^{+}$ & $3.4(-1)$ & $1.31(0)$ \\
$\mathrm{CO}+\mathrm{N} \rightarrow \mathrm{NO}^{+}+\mathrm{C}$ & $3.9(-2)$ & $5.3(-1)$ \\
$\mathrm{N}^{+}+\mathrm{CO} \rightarrow \mathrm{NO}^{+}+\mathrm{C}$ & $2.0(-2)$ & $6.2(-1)$ \\
$\mathrm{C}^{+}+\mathrm{NO} \rightarrow \mathrm{NO}^{+}+\mathrm{C}$ & $2.6(-2)$ & $1.16(-1)$ \\
Total & $4.3(2)$ & $1.64(3)$ \\
\hline
\end{tabular}

${ }^{\mathrm{a}}$ Rates are in $10^{6} \mathrm{~cm}^{-2} \mathrm{~s}^{-1}$

${ }^{\mathrm{b}}$ Read 3.2(2), for example, as $3.2 \times 10^{2}$. 


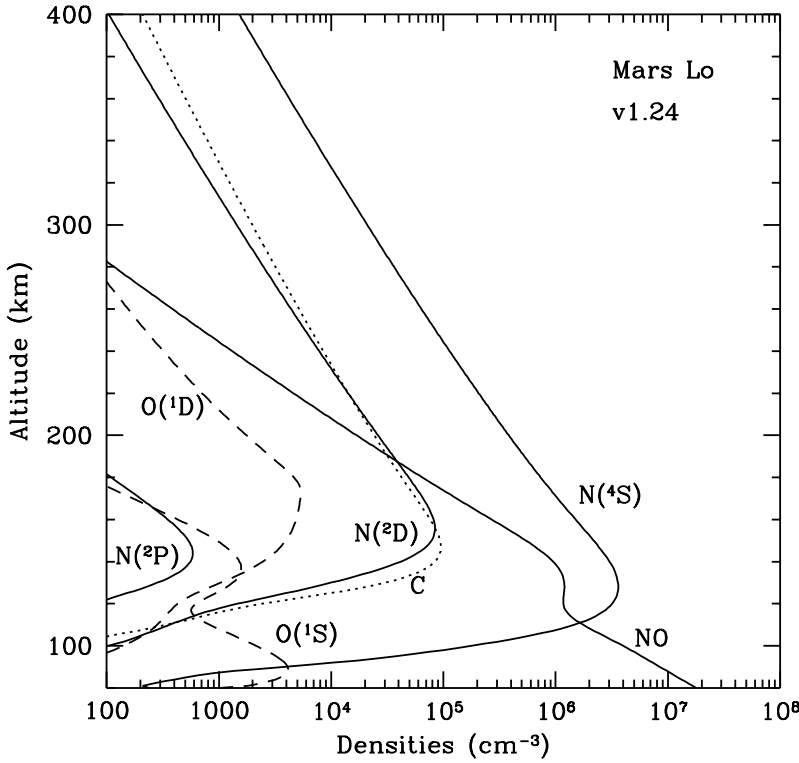

Figure 5. Altitude profiles of the densities of the minor neutral species in the low solar activity model. The solid curves are odd nitrogen $\left(\mathrm{NO}, \mathrm{N}, \mathrm{N}\left({ }^{2} D\right)\right.$, and $\left.\mathrm{N}\left({ }^{2} P\right)\right)$ density profiles, the dashed curves are the density profiles of $\mathrm{O}\left({ }^{1} D\right)$ and $\mathrm{O}\left({ }^{1} S\right)$, and the dotted curve is the density profile of $\mathrm{C}$.

of that amount, or $1.67 \mathrm{eV}$, appearing as translational energy of $\mathrm{C}$ in the center-of-mass frame. The escape energy of $\mathrm{C}$ from the Martian atmosphere is $\sim 1.48 \mathrm{eV}$. Thus dissociative recombination of $\mathrm{CO}_{2}^{+}$has the potential to provide an important source of escaping $\mathrm{C}$ atoms. It is highly likely, however, that the product $\mathrm{O}_{2}$ molecule is vibrationally and/or rotationally excited, especially since the $\mathrm{CO}_{2}^{+}+e$ system must be rearranged to form the new $\mathrm{O}-\mathrm{O}$ bond.

[18] No information is available about the kinetic energy of the $\mathrm{C}$ atom in reaction (1b) (L. Anderson, personal communication, 2004). We can estimate the energy distribution of the $\mathrm{C}$ atoms by assuming that the vibrationalrotational states of the resulting $\mathrm{O}_{2}$ molecule and the translational states of the $\mathrm{C}$ and $\mathrm{O}_{2}$ fragments are populated statistically. The statistical distribution can be computed using the methods of information theory [e.g., Levine and Bernstein, 1974, 1987]. The probability of production of an $\mathrm{O}_{2}$ molecule in a state with a vibrational quantum number $v$ and a rotational quantum number $J$ is given by

$$
P(v, J)=\frac{g_{v, J} \rho\left(E_{T}\right)}{\rho(E)},
$$

where $g_{v, J}$ is the degeneracy of the vibrational-rotational state, $\rho\left(E_{T}\right)$ is the density of states with translational energy $E_{T}$, and $\rho(E)$ is the density of states with total energy $E$. The translational density of states is proportional to the square root of the translational energy $\left(E_{T}\right)^{1 / 2}$. In the rotating oscillator approximation the rotational energy $E_{J}$ is given by

$$
E_{J}=B_{v} h c J(J+1),
$$

where

$$
B_{v}=B_{e}-\alpha_{e}(v+1 / 2) .
$$

In equations (4) and (5), $h$ is Planck's constant, $c$ is the speed of light, $B_{e}$ is the rotational constant for the equilibrium internuclear position, and $B_{v}$ is the rotational constant for vibrational level $v ; \alpha_{e}$ is a constant which accounts for the change in internuclear distance induced by the vibration of the molecule and which is small compared to $B_{e}$. The vibrational energy including the zero point energy is given by

$$
E_{v}=h c \omega_{e}(v+1 / 2)-h c \omega_{e} x_{e}(v+1 / 2)^{2},
$$

where $\omega_{e}$ is the harmonic oscillator frequency and $\omega_{e} x_{e}$ is the coefficient of the first term in the expansion for the energy of an anharmonic oscillator. Because the $2.3 \mathrm{eV}$ exothermicity applies to the product $\mathrm{O}_{2}$ molecule in the vibrational ground state, in computing the energy distribution we have subtracted the zero point energy $E_{0}$ from the vibrational energy. The constants $\alpha, B_{e}, \omega_{e}$, and $\omega_{e} x_{e}$ for $\mathrm{O}_{2}$ were taken from Herzberg [1950]. The total translational energy is given by the difference between the total energy $E$ and the internal energy of the $\mathrm{O}_{2}$ molecule,

$$
E_{T}=E-E_{v}-E_{J} .
$$

The total density of states is given by

$$
\rho(E)=\sum_{v} \sum_{J} g_{v, J} \rho_{T}\left(E-E_{v}-E_{J}\right),
$$

where the sums are overall energetically accessible values of $v$ and $J$. The degeneracy factor $g_{v, J}$ for $\mathrm{O}_{2}$ is equal to $2 J+$ 1 , and because of symmetry considerations the rotational quantum numbers $J$ for the ground $X^{3} \Sigma_{g}^{-}$state are limited to odd values.

[19] For statistical energy partitioning we find that $27 \%$ of the energy goes into vibrational energy above the zero point, $29 \%$ goes into rotational energy, and $44 \%$ goes into

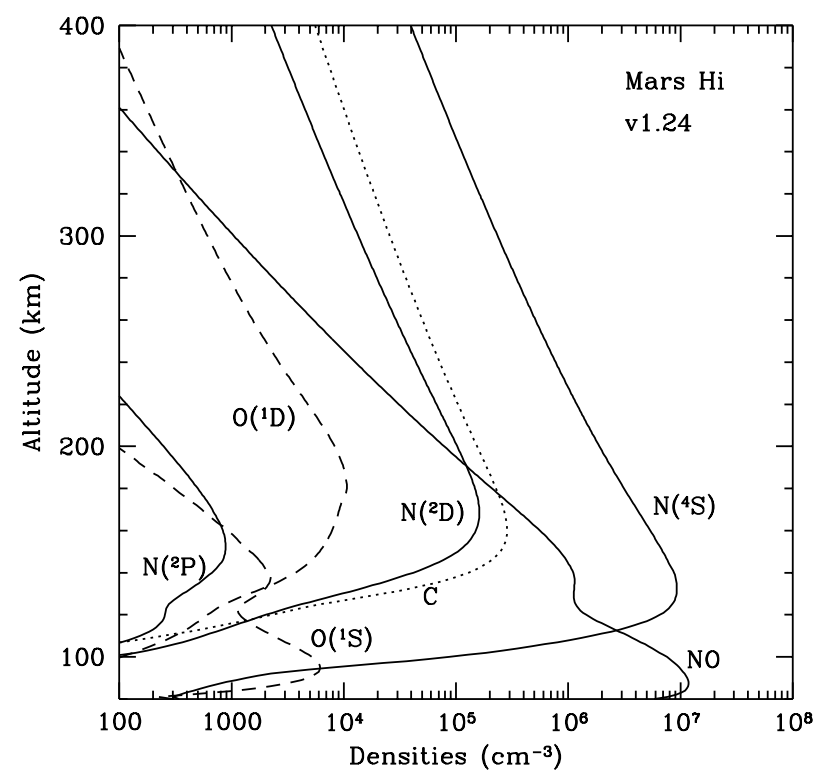

Figure 6. Same as for Figure 5 but for the high-solar activity model. 


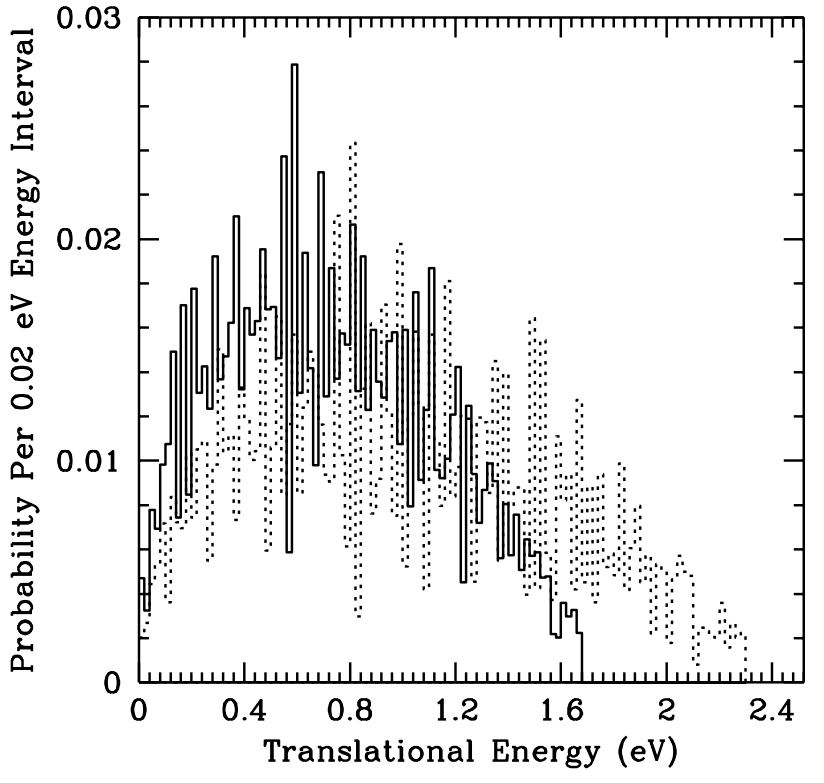

Figure 7. Statistical distribution of translational energies for the $\mathrm{C}$ atoms and for the $\mathrm{C}+\mathrm{O}_{2}$ produced in dissociative recombination of $\mathrm{CO}_{2}^{+}$. The probabilities are per 0.02 energy bin and are normalized so that the sum over the bins is equal to 1 . The solid histogram is the $\mathrm{C}$ translational energy distribution, and the dotted histogram is the total translational energy distribution of the products.

translational energy. The computed distribution of translational energies is shown in Figure 7, where the probabilities are binned in $0.02 \mathrm{eV}$ intervals and the sum of the probabilities over the bins is 1 . The solid histogram indicates the $\mathrm{C}$ translational energy, and the dotted histogram represents the total translational energy of the products $\mathrm{C}$ and $\mathrm{O}_{2}$. We find that for statistical energy partitioning, only $3.74 \%$ of the dissociative recombination reactions (reaction (1b)) produce $\mathrm{C}$ atoms with energies greater than the escape energy of $1.48 \mathrm{eV}$. This fraction would be larger if the translational energy distribution of the reactants for the ion and electron temperatures appropriate to the Martian ionosphere were taken into account, especially since the escape energy is near the tail of the distribution. On the other hand, vibrational distributions that are hotter than statistical distributions often result when a new bond is formed [e.g., Guillory et al., 1983]. In such cases the vibrational energy distribution may even be inverted, with higher vibrational levels more probable. In addition, the products of reaction (1b) may be formed in electronically excited electronic states. The energy of $C\left({ }^{1} D\right)$ above the $\mathrm{C}\left({ }^{3} P\right)$ ground state is $1.26 \mathrm{eV}$; the energy of the electronically excited state $\mathrm{O}_{2}\left({ }^{1} \Delta_{g}\right)$ is $0.98 \mathrm{eV}$ above the $\mathrm{O}_{2}\left(X^{3} \Sigma_{g}^{-}\right)$ground state. If either of the products is found in an electronically excited state, the energy available for translation of the $\mathrm{C}$ atom will be insufficient for escape. There is, however, no information about the electronic states of the products of reaction (1b). It is therefore not unreasonable to assume that only a small fraction of the $\mathrm{C}$ atoms produced in dissociative recombination of $\mathrm{CO}_{2}^{+}$have enough energy to escape.

[20] We can estimate the escape fluxes of $\mathrm{C}$ atoms due to various mechanisms using the exobase approximation.
In the exobase approximation the altitude region above the exobase is assumed to be collisionless. The escape flux is estimated by integrating the production rates of atoms with energies greater than the escape energy above the exobase and multiplying the result by 0.5 to account for the fraction released in the downward hemisphere. The exobase in the low and high solar activity models should be calculated as $1.3 / \sigma$, where $\sigma$ is the momentum transfer cross section [Johnson, 1994]. Since there is no information about either the collision or momentum transfer cross section of $\mathrm{C}$ with $\mathrm{O}, \mathrm{CO}_{2}$, or other species near the exobase of Mars, we adopt the traditional value of the collision cross section of $3 \times 10^{-15} \mathrm{~cm}^{2}$ as an average value for the collisions of $\mathrm{C}$ with other species. With this assumption the exobase in the low-solar activity model is located at $\sim 184 \mathrm{~km}$, and the exobase in the high-solar activity model is located at $\sim 220 \mathrm{~km}$. Recently, the atomic carbon escape rates computed with the exobase approximation have been shown to agree within a factor of 2 of those computed with preliminary three-dimensional Monte Carlo calculations [Bakalian and Fox, 2002]. If we assume that a fraction 0.04 of the $C$ atoms produced in reaction (1b) have energies greater than the escape energy, we obtain $\mathrm{C}$ escape fluxes due to dissociative recombination of $\mathrm{CO}_{2}^{+}$of $3.1 \times 10^{4}$ and $4.9 \times 10^{4} \mathrm{~cm}^{-2} \mathrm{~s}^{-1}$ for the low and high solar activity models, respectively. These escape fluxes are compared to those from the other major escape mechanisms in Table 2. The nonthermal $\mathrm{C}$ production rates differ substantially from the production rates of total $\mathrm{C}$, which are shown in Table 1. Although reaction (1b) is the most important source of total $\mathrm{C}$, it provides only $\sim 1-3 \%$ of the total escape fluxes of $\mathrm{C}$ in our models. The contribution to the escape flux of reaction (1b) is limited not only by the small expected energy released as translational energy but also, as Figures 3 and 4 show, by the rapid falloff of the altitude profile of this source near the exobase.

[21] We find that the major escape mechanism is photodissociation of $\mathrm{CO}$, as did Fox and Bakalian [2001] and Nagy et al. [2001]. The escape fluxes computed in both investigations are based on the similar production rates, but Nagy et al. [2001] used the twostream approximation rather than the exobase approximation in computing the escape fluxes. The predicted escape flux due to photodissociation in the current model is comparable to that found in previous models at high solar activity but is a factor of 2 larger at low solar activity. The second most important source of escaping $\mathrm{C}$ in the current model is electron impact dissociation of $\mathrm{CO}$ rather

Table 2. Escape Rates of C Atoms Due to Various Sources for the Low and High Solar Activity Models ${ }^{\mathrm{a}}$

\begin{tabular}{lcc}
\hline \multicolumn{1}{c}{ Mechanism } & Low Solar Activity & High Solar Activity \\
\hline $\mathrm{CO}+\mathrm{h} \nu \rightarrow \mathrm{C}+\mathrm{O}$ & 0.73 & 3.5 \\
$\mathrm{CO}+e \rightarrow \mathrm{C}+\mathrm{O}+e$ & 0.187 & 1.76 \\
$\mathrm{CO}^{+}+e \rightarrow \mathrm{C}+\mathrm{O}$ & 0.128 & 0.77 \\
$\mathrm{CO}+\mathrm{h} \nu \rightarrow \mathrm{C}+\mathrm{O}^{+}+e$ & 0.036 & 0.34 \\
$\mathrm{CO}+e \rightarrow \mathrm{C}+\mathrm{O}_{2}^{+}$ & 0.031 & 0.049 \\
$\mathrm{CO}+e \rightarrow \mathrm{C}+\mathrm{O}^{+}+2 e$ & 0.00164 & 0.0183 \\
Total & 1.11 & 6.4 \\
\hline
\end{tabular}

${ }^{a}$ Rates are in $10^{6} \mathrm{~cm}^{-2} \mathrm{~s}^{-1}$. Global average escape fluxes are approximately half the values shown. 
than dissociative recombination of $\mathrm{CO}^{+}$. Only these three mechanisms, however, contribute significantly to the total escape flux.

[22] A detailed analysis of the differences among the escape fluxes we compute here and those calculated by Fox and Bakalian [2001] and Nagy et al. [2001] is difficult. There are several differences among the three models that contribute to the differences among the predicted escape fluxes. The current models are based on different solar fluxes, which are characterized by both different EUV fluxes and enhanced soft X-ray fluxes. The solar fluxes adopted here are the 76200 and 79050 S2K v1.24 fluxes of Tobiska [2004], which are based on the soft X-ray fluxes measured by the SNOE SXP. Fox and Bakalian [2001] adopted the SC\#21REFW and F79050 solar flux spectra of H. E. Hinteregger (personal communication, 1981) [see also Torr et al., 1979] for the low and high solar activity models, respectively. The exobase altitudes are slightly lower in the current model than in previous models. In addition, we have adopted a mixing ratio for $\mathrm{H}_{2}$ of $10 \mathrm{ppm}$ rather than the value of $40 \mathrm{ppm}$ in the previous models. As Fox [2001, 2003a] showed, because the ions react with $\mathrm{H}_{2}$, the density profiles of $\mathrm{N}_{2}^{+}$, $\mathrm{CO}^{+}, \mathrm{CO}_{2}^{+}$, and $\mathrm{O}^{+}$are highly dependent on the $\mathrm{H}_{2}$ mixing ratio at low solar activity. Because of the larger ion densities this effect is less at high solar activity. We have also adopted a dissociative recombination coefficient for $\mathrm{CO}_{2}^{+}$that is larger at thermal energies than that adopted previously, but it also has a larger negative temperature dependence. The larger rates of production of escaping $\mathrm{C}$ by photodissociative ionization and electron impact dissociative ionization of $\mathrm{CO}$ are probably related to the increased fluxes of short-wavelength photons in the solar spectra that we employ here and the concomitant increased production of energetic photoelectrons. Dissociative ionization of $\mathrm{CO}$,

$$
\mathrm{CO}+(h \nu, e) \rightarrow \mathrm{C}+\mathrm{O}^{+}+(e, 2 e),
$$

has a threshold of $\sim 24.7 \mathrm{eV}$, or $500 \AA$ and is thus more sensitive to the shorter-wavelength solar fluxes and to high-energy electrons than photodissociation. The threshold for photodissociation of $\mathrm{CO}$ is $1118 \AA$, and the cross sections become negligible shortward of $600 \AA$. The contributions of photodissociative ionization and electron impact dissociative ionization, however, are still small compared to the major sources of hot $\mathrm{C}$. The larger photodissociation rates of $\mathrm{CO}$ in the low solar activity model can be ascribed to the different solar fluxes. The optically thin $\mathrm{CO}$ photodissociation frequencies for the Hinteregger SC\#21REFW and S2K v1.24 76200 spectra at the mean heliocentric distance of Mars are $1.61 \times$ $10^{-7}$ and $2.78 \times 10^{-7} \mathrm{~s}^{-1}$, respectively.

[23] The total escape fluxes of $\mathrm{C}$ for our $60^{\circ}$ solar zenith angle model are $(1.1-6.4) \times 10^{6} \mathrm{~cm}^{-2} \mathrm{~s}^{-1}$, where the range is from low to high solar activity. Except for a factor of 2 difference at low solar activity these values compare favorably with the hemispheric escape fluxes of Fox and Bakalian [2001] and Nagy et al. [2001], which are in the ranges $(0.42-5.2) \times 10^{6}$ and $(0.53-7.7) \times$ $10^{6} \mathrm{~cm}^{-2} \mathrm{~s}^{-1}$, respectively. The larger values at low solar activity are primarily related to the larger rate of photodissociation of $\mathrm{CO}$ at low solar activity.

\section{Conclusions}

[24] We have included the recently measured rate coefficient for the production of $\mathrm{C}$ in dissociative recombination of $\mathrm{CO}_{2}^{+}$(reaction (1b)) in both low and high solar activity models of the Martian thermosphere/ionosphere. We find that the reaction is the dominant source of atomic carbon in both models, and its inclusion leads to larger densities of ambient $\mathrm{C}$ if the branching ratio for the reaction is near the value of $\sim 0.09$ reported by Seiersen et al. [2003]. On the other hand, the source of escaping $\mathrm{C}$ is probably small both because of the altitude profile of the source, which falls off rapidly in the exobase region, and because the $\mathrm{O}_{2}$ molecule is probably produced with considerable internal energy. We have calculated the statistical energy partitioning into vibrational and rotational energy of the product $\mathrm{O}_{2}$ molecule and the translation energy of the products of the reaction. We find that the $\mathrm{C}$ atom is produced with translational energy exceeding the escape energy only $3.7 \%$ of the time. In addition, if the $\mathrm{C}$ and $\mathrm{O}_{2}$ molecules are electronically excited, the available translational energy would be reduced to less than the escape energy of $\mathrm{C}$. Although the computed escape rates of $\mathrm{C}$ for the minor mechanisms are much different from those in previous models, the dominant escape mechanism is still photodissociation of $\mathrm{CO}$, followed by electron impact dissociation of $\mathrm{CO}$ and dissociative recombination of $\mathrm{CO}^{+}$. The total predicted escape fluxes are comparable to those of previous models at high solar activity and are a factor of 2 larger at low solar activity. The latter result is ascribed to the use of different solar fluxes in the models.

[25] Acknowledgments. This work has been supported by grants NAG5-12755 and MAG5-13313 from the National Aeronautics and Space Administration and by grant AST-9802007 from the National Science Foundation to Wright State University.

[26] Arthur Richmond thanks Andrew F. Nagy and another reviewer for their assistance in evaluating this paper.

\section{References}

Anderson, D. E., and C. W. Hord (1971), Mariner 6 and 7 ultraviolet spectrometer experiment: Analysis of hydrogen Lyman alpha, J. Geophys. Res., 76, 6666-6673.

Ayres, T. R. (1997), Evolution of the solar ionizing flux, J. Geophys. Res., $102,1641-1651$.

Bailey, S. M., T. N. Woods, C. A. Barth, S. C. Solomon, L. R. Canfield, and R. Korde (2000), Measurements of the solar soft X-ray irradiance by the Student Nitric Oxide Explorer: First analysis and underflight calibrations, J. Geophys. Res., 105, 27,179-27,193.

Bakalian, F. M., and J. L. Fox (2002), Comparison of a Monte Carlo calculation of the escape rate of $\mathrm{C}$ from Mars to that obtained using the exobase approximation, Eos Trans. $A G U, 83(19)$, Spring Meet. Suppl., Abstract SA41A-23.

Barth, C. A., C. W. Hord, J. B. Pearce, K. K. Kelly, G. P. Anderson, and A. I. Stewart (1971), Mariner 6 and 7 ultraviolet spectrometer experiment: Upper atmospheric data, J. Geophys. Res., 76, 2213-2227.

Barth, C. A., C. W. Hord, A. I. Stewart, and A. L. Lane (1972a), Mariner Ultraviolet spectrometer experiment: Initial results, Science, 175, 309312

Barth, C. A., A. I. Stewart, C. W. Hord, and A. L. Lane (1972b), Mariner 9 ultraviolet spectrometer experiment: Mars airglow spectroscopy and variations in Lyman alpha, Icarus, 17, 457-468.

Barth, C. A., S. M. Bailey, and S. C. Solomon (1999), Solar-terrestrial coupling: Solar soft X-rays and thermospheric nitric oxide, Geophys. Res. Lett., 26, 1251-1254. 
Bougher, S. W., R. G. Roble, E. C. Ridley, and R. E. Dickinson (1990), The Mars thermosphere: 2. General circulation with coupled dynamics and composition, J. Geophys. Res., 95, 14,811-14,827

Bougher, S. W., S. Engel, R. G. Roble, and B. Foster (1999), Comparative terrestrial planet thermospheres: 2. Solar cycle variation of global structure and winds at equinox, J. Geophys. Res., 104, $16,591-16,611$.

Bougher, S. W., S. Engel, R. G. Roble, and B. Foster (2000), Comparative terrestrial planet thermospheres: 3 . Solar cycle variation of global structure and winds at solstices, J. Geophys. Res., 105, 17,669-17,692.

Chamberlain, J. W. (1963), Planetary coronae and atmospheric evaporation, Planet. Space Sci., 11, 901-960.

Chen, R. H., T. E. Cravens, and A. F. Nagy (1978), The Martian ionosphere in light of the Viking observations, J. Geophys. Res., 83, 3871-3876.

Fjeldbo, G., A. Kliore, and B. Seidel (1970), The Mariner 1969 occultation measurements of the upper atmosphere of Mars, Radio Sci., 5, 381-386.

Fox, J. L. (1982), Atomic carbon in the atmosphere of Venus, J. Geophys. Res., 87, 9211-9216.

Fox, J. L. (1993), The production and escape of nitrogen atoms on Mars, J. Geophys. Res., 98, 3297-3310.

Fox, J. L. (1997), Upper limits to the outflow of ions at Mars: Implications for atmospheric evolution, Geophys. Res. Lett., 24, 2901-2904.

Fox, J. L. (2001), The effect of enhanced hydrogen on the nonthermal escape of atoms, Eos Trans. AGU, 82(20), Spring Meet. Suppl., Abstract P41A-04.

Fox, J. L. (2003a), The effect of $\mathrm{H}_{2}$ on the Martian ionosphere: Implications for atmospheric evolution, J. Geophys. Res., 108(A6), 1223, doi:10.1029 2001JA000203

Fox, J. L. (2003b), The effects of enhanced fluxes of soft X-rays on the ionospheres and thermospheres of Venus and Mars, Eos Trans. $A G U$, 84(46), Fall Meet. Suppl., Abstract A12A-70.

Fox, J. L., and F. M. Bakalian (2001), Photochemical escape of atomic carbon from Mars, J. Geophys. Res., 106, 28,785-28,796.

Fox, J. L., and A. Dalgarno (1979), Ionization, luminosity, and heating of the upper atmosphere of Mars, J. Geophys. Res., 84, 7315-7333.

Fox, J. L., and K. Y. Sung (2001), Solar activity variations of the Venus thermosphere/ionosphere, J. Geophys. Res., 106, 21,305-21,335.

Fox, J. L., and G. A. Victor (1981), $\mathrm{O}^{++}$in the Venusian ionosphere, J. Geophys. Res., 86, 2438-2442.

Fox, J. L., P. Zhou, and S. W. Bougher (1995), The thermosphere/ ionosphere of Mars at high and low solar activities, Adv. Space Res., 17, 11,203-11,218

Geoghegan, M., N. G. Adams, and D. Smith (1991), Determination of the electron-ion dissociative recombination coefficient for several molecularions at $300 \mathrm{~K}$, J. Phys. B At. Mol. Opt. Phys., 24, 2589-2599.

Gougousi, T., M. F. Golde, and R. Johnsen (1997), Electron-ion recombination rate coefficient measurements in a flowing afterglow plasma, Chem. Phys. Lett., 265, 399-403.

Guillory, W. A., K. H. Gericke, and F. J. Comes (1983), The dynamics of the reaction of ${ }^{16} \mathrm{O}\left({ }^{1} D\right)+\mathrm{D}_{2}^{18} \mathrm{O} \rightarrow{ }^{16} \mathrm{OD}+{ }^{18} \mathrm{OD}$, J. Chem. Phys., 78, $5993-6001$

Gutcheck, R. A., and E. C. Zipf (1973), Excitation of the CO fourth positive system by the dissociative recombination of $\mathrm{CO}_{2}^{+}$ions, J. Geophys. Res., $78,5429-5436$

Hanson, W. B., S. Sanatani, and D. R. Zuccaro (1977), The Martian ionosphere as observed by the Viking retarding potential analyzers, J. Geophys. Res., 82, 4351-4367.

Herzberg, G. (1950), Molecular Spectra and Molecular Structure: Spectra of Diatomic Molecules, Van Nostrand Reinhold, New York.

Johnson, R. E. (1994), Plasma-induced sputtering of an atmosphere, Space Sci. Rev., 69, 215-253.

Krasnopolsky, V. A. (1982), Atomic carbon in the atmospheres of Venus and Mars, Cosmic Res., Engl. Transl., 20, 430-437.
Krasnopolsky, V. A., and P. D. Feldman (2001), Detection of molecular hydrogen in the atmosphere of Mars, Science, 294, 1914-1917.

Krasnopolsky, V. A., M. J. Mumma, and G. R. Gladstone (1998), Detection of atomic deuterium in the upper atmosphere of Mars, Science, 280, $1576-1580$.

Larsson, M. (1997), Dissociative recombination with ion storage rings, Annu. Rev. Phys. Chem., 48, 151-179.

Levine, R. D., and R. B. Bernstein (1974), Energy disposal and energy consumption in elementary chemical reactions: The information theoretic approach, Acc. Chem. Res., 7, 393-400.

Levine, R. D., and R. B. Bernstein (1987), Molecular Reaction Dynamics and Chemical Reactivity, Oxford Univ. Press, New York.

Liu, Y., A. F. Nagy, T. I. Gombosi, D. L. DeZeeuw, and K. G. Powell (2001), The solar wind interaction with Mars: Results of three-dimensional threespecies MHD studies, Adv. Space Res., 27, 1837-1846.

Ma, Y., A. F. Nagy, K. C. Hansen, D. L. DeZeeuw, and K. G. Powell (2002), Three-dimensional multispecies MHD studies of the solar wind interaction with Mars in the presence of crustal fields, J. Geophys. Res., 107(A10), 1282, doi:10.1029/2002JA009293.

McElroy, M. B., and J. C. McConnell (1971), Atomic carbon in the atmospheres of Mars and Venus, J. Geophys. Res., 76, 6674-6690.

McElroy, M. B., T. Y. Kong, Y. L. Yung, and A. O. Nier (1976), Composition and structure of the Martian atmosphere: Analysis and results from Viking, Science, 194, 1295-1298.

Nagy, A. F., M. W. Liemohn, J. L. Fox, and J. Kim (2001), Hot carbon densities in the exosphere of Mars, J. Geophys. Res., 106, 21,56521,568 .

Nier, A. O., and M. B. McElroy (1976), Structure of the neutral upper atmosphere of Mars: Results from Viking 1 and Viking 2, Science, $194,1298-1300$

Seiersen, K., A. Al-Khalili, O. Heber, M. J. Jensen, I. B. Nielsen, H. B. Pedersen, C. P. Safvan, and L. H. Andersen (2003), Dissociative recombination of the cation and dication of $\mathrm{CO}_{2}$, Phys. Rev. A, 68(2), 022708.

Shinagawa, H., and T. E. Cravens (1989), A one-dimensional multispecies magnetohydrodynamic model of the dayside ionosphere of Mars, J. Geophys. Res., 94, 6506-6516.

Shizgal, B., and R. Blackmore (1986), A collisional kinetic theory of a plane parallel evaporating planetary atmosphere, Planet. Space Sci., 34, $279-291$

Skrzypkowski, M. P., T. Gougousi, R. Johnsen, and M. F. Golde (1998), Measurement of the absolute yield of $\mathrm{CO}\left(a^{3} \Pi\right)+\mathrm{O}$ products in the dissociative recombination of $\mathrm{CO}_{2}^{+}$ions with electrons, J. Chem. Phys., $108,8400-8407$

Tobiska, W. K. (2004), SOLAR2000 irradiances for climate change, aeronomy and space system engineering, Adv. Space. Res., in press.

Torr, M. R., D. G. Torr, R. A. Ong, and H. E. Hinteregger (1979), Ionization frequencies for major thermospheric constituents as a function of solar cycle 21, Geophys. Res. Lett., 6, 771-774.

Tsuji, M., M. Nakamura, and Y. Nishimura (1995), Nascent rovibrational distribution of $\mathrm{CO}\left(A^{1} \Pi\right)$ produced in the recombination of $\mathrm{CO}_{2}^{+}$with electrons, J. Chem. Phys, 103, 1413-1421.

Verner, D. A., and D. G. Yakovlev (1995), Analytic fits for partial photoionization cross sections, Astron. Astrophys. Suppl. Ser., 109, 125-133.

Wauchop, T. S., and H. P. Broida (1972), Lifetime and quenching of $\mathrm{CO}\left(\mathrm{a}^{3} \Pi\right)$ produced by recombination of $\mathrm{CO}_{2}$ ions in a helium afterglow, J. Chem. Phys., 56, 330-332.

Woods, T. N., et al. (2000), TIMED Solar EUV Experiment, Phys. Chem. Earth, Part C, 25, 393-396.

J. L. Fox, Department of Physics, Wright State University, Dayton, $\mathrm{OH}$ 45435, USA. (jane.fox@wright.edu) 